\title{
Effect of excluded volume on the dipole moments of chain molecules
}

\author{
S. C. Liao and J. E. Mark \\ Department of Chemistry and the Macromolecular Research Center, University of Michigan, Ann Arbor, Michigan 48104
}

(Received 4 June 1973)

\begin{abstract}
Dielectric constants have been determined for dimethylsiloxane chains $\left(\mathrm{CH}_{3}\right)_{3} \mathrm{Si}\left[\mathrm{OSi}\left(\mathrm{CH}_{3}\right)_{2}\right]_{x} \mathrm{OSi}\left(\mathrm{CH}_{3}\right)_{3}$ in the thermodynamically good solvent cyclohexane and in the undiluted state, for degrees of polymerization $x+1$ ranging from $10^{2}$ to $10^{3}$, at a number of temperatures in the range $10-60^{\circ} \mathrm{C}$. These data indicate that at constant temperature the dipole moment ratio $\left\langle\mu^{2}\right\rangle / n m^{2}$ (where $\left\langle\mu^{2}\right\rangle$ is the mean-square dipole moment of a chain consisting of $n=2 x+2$ bond dipoles of magnitude $m$ ) is independent of chain length, as has been predicted for chains of such structural symmetry.

Unfortunately, comparison of the experimental values of the dipole moment ratio with those predicted from rotational isomeric state theory is complicated by pronounced specific solvent effects and comparison of experimental and theoretical values of $d \ln \left\langle\mu^{2}\right\rangle / d T$ is also difficult because of the very small magnitude of this coefficient.
\end{abstract}

\section{INTRODUCTION}

The quantity most widely used to characterize random-coil configurations of chain molecules ${ }^{1}$ is the characteristic ratio $\left\langle r^{2}\right\rangle_{0} / n l^{2}$, where $\left\langle r^{2}\right\rangle_{0}$ is the mean-square end-to-end distance of the chain as unperturbed by long-range interactions ("excluded volume effects" $)^{2-5}$ and $n$ is the number of skeletal bonds, each of length $l$. The requirement that the molecule be in its unperturbed state stems from the desire that its dimensions truly reflect the nature of the chain with regard to its structural geometry and short-range intramolecular interactions (and not extraneous effects arising from longrange intramolecular interactions between parts of the same chain and intermolecular interactions between the chain molecule and the molecules of a solvent medium in which it is customarily studied). The necessary and sufficient condition which assures the absence of such perturbations is that the polymer-solvent system be studied at the temperature $\Theta^{4,5}$ at which the effects of the two cited interactions cancel one another. Under this condition, the ratio $\left\langle r^{2}\right\rangle_{0} / n l^{2}$ converges with increasing chain length to a (constant) value characteristic of the chain molecule at the specified temperature and it is this quantity which is then directly interpretable in terms of rotational isomeric state theory. ${ }^{1}$

The dielectric analog of $\left\langle r^{2}\right\rangle_{0} / n l^{2}$ is the dipole moment ratio $\left\langle\mu^{2}\right\rangle_{0} / \mathrm{nm}^{2}$, where $\left\langle\mu^{2}\right\rangle_{0}$ is the meansquare dipole moment of the chain, similarly unperturbed by long-range interactions, and $n$ is the number of bond dipoles in the chain, each of magnitude $m$. This quantity is extremely useful in characterizing chain molecules ${ }^{6-19}$ since not only does it provide information supplementary to that contained in $\left\langle r^{2}\right\rangle_{0} / n l^{2}$ but $\left\langle\mu^{2}\right\rangle_{0} / n m^{2}$, unlike many other configuration-dependent properties, can readily be measured over the entire range of chain length. Of primary relevance here, however, is the fact that theory ${ }^{20-23}$ indicates that excluded volume interactions should have no effect on the dipole moments of chain molecules which possess certain symmetry features. (The advantage of such a simplification is obvious; dipole moments suitable for theoretical interpretation, for example, by rotational isomeric state theory, would not need to be determined under $\Theta$ conditions. Measurements in any nonpolar solvent would suffice and $\left\langle\mu^{2}\right\rangle$ would equal $\left\langle\mu^{2}\right\rangle_{0}$ under all conditions of experimental investigation.) The condition required for this circumstance, as originally stated by Marchal and Benoit, is that the resultant dipole moment of each repeat unit in the chain lie within a plane bisecting the bond angle of one of the skeletal atoms. ${ }^{20,21}$ Examples of chain molecules meeting this requirement include poly (oxyethylene), poly (dimethylsiloxane), and the poly(vinyl halides). Nagai and Ishikawa, ${ }^{22}$ however, have recently shown that this requirement can be generalized to include chain molecules having appropriate symmetry elements (planes, axes, points), for example, the poly(acry lates), poly(methacrylates), and the poly(amides). It is thus of considerable interest to test these the eretical predictions by appropriate experimental investigation.

The most direct such experimental test is to determine experimental values of $\left\langle\mu^{2}\right\rangle / \mathrm{nm}^{2}$ as a function of chain length for a molecule meeting the stated structural requirements, in a "thermody namically good" solvent, i.e., one well above the $\Theta$ temperature for the chosen polymer-solvent system. Absence of excluded volume effects would be indicated by insensitivity of this ratio to chain length, once one has exceeded the region of very short chain length where the chains are not representative and end groups contribute significantly to the properties of the chain molecule. Unfortunately, it has not been recognized that in such an ex- 
periment all of the following additional conditions must be met. The fractions or whole polymers studied should vary only in their chain length; there should for example, be no possibility of complicating variation in stereochemical structure as well. At least several samples of different chain lengths should be studied and these chain lengths should be sufficiently large and should cover a sufficiently wide range of values that excluded volume effects, if present, would be readily discernible. Of the various studies ${ }^{6,16,20,24-43}$ which have been carried out to test this prediction or which merely report values of $\left\langle\mu^{2}\right\rangle$ as a function of chain length for a polymer of interest for other reasons, none are definitive with respect to the effect of excluded volume on the dipole moment since none meet all of the requirements cited above. Furthermore, a number of these studies give contradictory results with regard to the question at hand. For example, De Brouckère and Lecocq-Robert ${ }^{36}$ find $\left\langle\mu^{2}\right\rangle / \mathrm{nm}^{2}$ to be essentially independent of chain length for poly (methyl methacrylate), but Le Fèvre and Sundaram find this ratio to increase by approximately $10 \%$ for an increase in degree of polymerization from 500 to 2000 in the case of poly (vinyl chloride $)^{38}$ and by approximately $60 \%$ for an increase in degree of polymerization from 100 to 350 in the case of poly (vinyl bromide). ${ }^{39}$ Such disagreements are scarcely surprising in view of the fact that most of the studies cited ${ }^{6,16,20,24-43}$ were carried out on vinyl polymers and of these studies on vinyl chains almost none take into account possible variation in stereochemical structure in the samples investigated. In fact, in a number of cases, the fractionation techniques employed would unquestionably cause the desired separations to occur on the basis of stereochemical composition as well as chain length. ${ }^{44}$ Since it is now well established ${ }^{17,19}$ that the dipole moment of a polar vinyl polymer can depend very markedly on stereochemical composition, the experimental results given in such studies are essentially uninterpretable.

Similarly, studies ${ }^{20,45}$ attempting to evaluate excluded volume effects by determining $\left\langle\mu^{2}\right\rangle / \mathrm{nm}^{2}$ for the same sample of polymer in a variety of solvents which give very different values of $\left\langle r^{2}\right\rangle / n l^{2}$ are not entirely conclusive because of the likelihood of specific solvent effects ${ }^{46-52}$ on the dipole moment. An example of the possible origin of such a complication would be the change in the Coulombic contribution to the short-range, intramolecular interactions along the chain due to changes in the dielectric constant of the medium. An effect of this nature would of course assume particular importance in the case of significantly polar polymers and obviously can not be corrected for by simple adjustment ${ }^{20,45}$ of the bond dipole mo- ment $m$ in correspondence with changes observed for the dipole moment of the (saturated) monomeric unit in the same series of solvents. These studies ${ }^{20,31,45,53,54}$ are therefore also somewhat ambiguous with regard to the possible importance of excluded volume effects on $\left\langle\mu^{2}\right\rangle / n m^{2}$.

In view of the uncertainties cited above, it becomes highly desirable to obtain more definitive experimental results bearing on this problem. An ideal polymer for such a study is poly (dimethylsiloxane) (PDMS), $\left(\mathrm{CH}_{3}\right)_{3} \mathrm{Si}\left[\mathrm{OSi}\left(\mathrm{CH}_{3}\right)_{2}\right]_{x} \mathrm{OSi}\left(\mathrm{CH}_{3}\right)_{3}$, a chain molecule without stereochemical variability which also has dipole moments sufficiently large $e^{13,16,43,55,56}$ to be easily measurable. The purpose of the present study is, therefore, to measure dipole moments of PDMS chains in a thermody namically good solvent, cyclohexane, for degrees of polymerization $x+1$ ranging from $10^{2}$ to $10^{3}$. This range of chain lengths is quite suitable in that excluded volume effects, if present, should be readily discernible. In addition, PDMS chains in this range are sufficiently fluid to make feasible measurements on the undiluted polymer; such measurements can be used to determine the magnitude of specific solvent effects, already known to be important for these molecules both in the isolated state in dilute solution ${ }^{51}$ and in solvent-swollen, cross-linked networks. ${ }^{57}$ The dielectric measurements are carried out at a number of temperatures in the range $10-60^{\circ} \mathrm{C}$, thus also permitting estimation of the coefficient $d \ln \left\langle\mu^{2}\right\rangle / d T$ for these chain molecules. The experimental values of both $\left\langle\mu^{2}\right\rangle / n m^{2}$ and $d \ln \left\langle\mu^{2}\right\rangle / d T$ may then be compared with theoretical values ${ }^{13,16}$ of these quantities calculated from rotational isomeric state theory.

\section{EXPERIMENTAL DETAILS}

\section{Materials}

Fractions of PDMS of relatively narrow molecular weight distribution were obtained by standard fractional precipitation techniques; the solvent employed was benzene, the nonsolvent was methanol, the solutions contained approximately $10 \%$ by weight of polymer, and the fractionation was carried out at room temperature. In this way four fractions were obtained, each constituting about $20 \%$ by weight of one of the samples ${ }^{58}$ of which it had been a part. For purposes of comparison, a portion of one of the whole polymers (unfractionated) was set aside, to be included in some of the measurements.

The solvents used for calibration of the dielectric apparatus were cyclohexane, benzene, and carbon tetrachloride, with the first of these also serving as the solvent for the dielectric measurements on PDMS chains in solution. All of these 
solvents were chromatographic grade and were dried over Linde molecular sieves (type 4A) and distilled immediately prior to their use. The solvent used in the viscometric determinations of molecular weights was simply reagent-grade toluene.

The densities of the polymers and the solvents, cyclohexane and toluene, were determined at each temperature of interest by means of pycnometry. The temperatures chosen were $10,15,20,25,30$, 40,50 , and $60^{\circ} \mathrm{C}$ and were controlled to $\pm 0.01^{\circ}$.

\section{Viscometric Measurements}

Intrinsic viscosities $[\eta]$ used to determine molecular weights $M$ of the PDMS chains were deter mined in toluene at $25^{\circ} \mathrm{C}$ in the customary manner, ${ }^{4}$ using a Cannon-Ubbelohde viscometer (model OBA455). Preliminary measurements indicated that kinetic energy corrections to the viscometric data were negligible for this viscometer, under the experimental conditions employed. All solutions were prepared by weighing both polymer and solvent; preliminary, direct measurements indicated that the volumes of polymer and solvent (toluene or cyclohexane) were to a good approximation simply additive and most solution concentrations were calculated on this basis. Five separately prepared solutions, with concentrations in the range 1.0$6.0 \mathrm{~g} / \mathrm{dl}$, were used for each polymer. Values of $[\eta]$ were then determined from these data, using the usual extrapolation techniques. ${ }^{4}$

\section{Dielectric Measurements}

The apparatus and the techniques employed to measure the dielectric constants have been described in detail elsewhere. ${ }^{16}$ Measurements were carried out at $2 \mathrm{MHz}$, a frequency at which the dielectric constant obtained is to good approxima$\operatorname{tion}^{43}$ the static value $\epsilon_{0}$. The apparatus was calibrated at each temperature of interest using cyclohexane, benzene, carbon tetrachloride, and mois ture-free air, all of these being substances of known dielectric constant. ${ }^{59-61}$ Each solution used in the dielectric measurements was separately prepared and had a weight fraction $w_{2}$ of polymer in the range $0.007-0.030$. Five solutions were studied for each polymer.

Refractive indices of the polymers and the poly mer solutions were determined at 436 and $589 \mathrm{~m} \mu$ at each temperature of interest using a Bausch and Lomb precision refractometer of the Abbe design. The specific volumes $v$ of the solutions, quantities required in the analysis of the dielectric data, were either obtained directly by pycnometry or indirectly by assuming additivity of volumes of polyr er and solvent.

\section{RESULTS AND DISCUSSION}

The molecular weights of the polymers studied were calculated from their intrinsic viscosities in toluene at $25^{\circ} \mathrm{C}$ using the relationship

$$
[\eta]=2.00 \times 10^{-4} M^{0.66}
$$

determined by Barry ${ }^{62}$ from viscometric and osmometric measurements on PDMS chains having molecular weights ranging from $2.5 \times 10^{3}$ to $2.0 \times 10^{5}$, and verified by Korolev and co-workers $\mathrm{s}^{63}$ over the range $2.0 \times 10^{4}$ to $1.3 \times 10^{6}$. Molecular weights thus calculated gave degrees of polymerization $x+1$ of $97,188,239$, and 1038 for the polymer fractions and 162 for the unfractionated polymer.

The static dielectric constants and specific volumes for the polymers in cyclohexane were plotted as a function of weight fraction of polymer in order to obtain the coefficients $d \epsilon_{0} / d w_{2}$ and $d v / d w_{2}$ in the limit $w_{2} \rightarrow 0$; illustrative results, pertaining to $25{ }^{\circ} \mathrm{C}$, are shown in the second and third colums of Table I. Analogous quantities, pertaining to the polymers in the undiluted state, are shown in the remaining part of the table. The index of refraction $n_{\infty}$ at infinite wavelength was obtained from the experimen tal data at two wavelengths using the customary extrapolation techniques. ${ }^{43,64}$ These results on PDMS chains in the undiluted state are shown as a function of degree of polymerization in Fig. 1; the results for very short chains are taken from the literature ${ }^{16,43,56}$ and are included simply to show how rapidly $\epsilon_{0}, n_{\infty}$, and $v$ approach the limiting, constant values observed for degrees of polymerization exceeding 100. As can be seen from these results, the unfractionated polymer does not differ significantly in any respect from the polymer fractions and therefore no further distinctions will be made among the five PDMS samples studied.

The total molar polarization $P$ of the PDMS fractions in cyclohexane at each temperature was calculated from the Halverstadt and Kumler equation $^{65}$ :

TABLE I. Experimental data on $\left(\mathrm{CH}_{3}\right)_{3} \mathrm{Si}-$ [OSi $\left.\left(\mathrm{CH}_{3}\right)_{2}\right]_{x} \mathrm{OSi}\left(\mathrm{CH}_{3}\right)_{3}$ chains at $25^{\circ} \mathrm{C}$.

\begin{tabular}{cccccc}
\hline \multicolumn{3}{c}{ Sol'n } & & \multicolumn{3}{c}{ Undiluted } \\
$x+1$ & $d \epsilon_{0} / d w_{2}$ & $-d v^{\mathrm{a}} / d w_{2}$ & $\epsilon_{0}$ & $n_{\infty}$ & $v^{\mathrm{a}}$ \\
\hline 97 & 0.540 & 0.257 & 2.7375 & 1.3908 & 1.0353 \\
$162^{\mathrm{b}}$ & $\cdots$ & $\cdots$ & 2.7392 & 1.3909 & 1.0343 \\
188 & 0.560 & 0.256 & 2.7390 & 1.3910 & 1.0325 \\
239 & 0.545 & 0.260 & 2.7416 & 1.3914 & 1.0320 \\
1038 & 0.545 & 0.263 & 2.7517 & 1.3917 & 1.0293 \\
\hline
\end{tabular}

${ }^{2}$ Specific volume in $\mathrm{cm}^{3} \mathrm{~g}^{-1}$.

${ }^{b}$ Unfractionated polymer. 


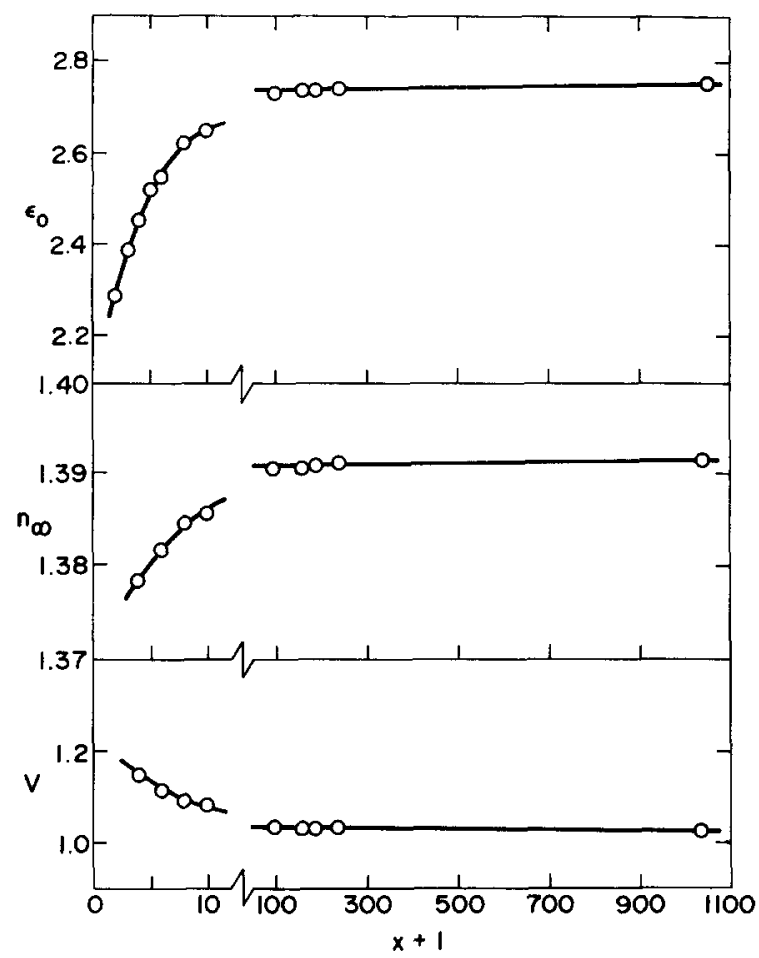

FIG. 1. The effect of the degree of polymerization $x$ +1 on the static dielectric constant, index of refraction at infinite wavelength, and specific volume of undiluted dimethylsiloxane chains $\left(\mathrm{CH}_{3}\right)_{3} \mathrm{Si}\left[\mathrm{OSi}\left(\mathrm{CH}_{3}\right)_{2}\right]_{x} \mathrm{OSi}\left(\mathrm{CH}_{3}\right)_{3}$, at $25^{\circ} \mathrm{C}$

$$
\begin{aligned}
P=\left[3 M v_{1} /\left(\epsilon_{1}+2\right)^{2}\right]\left(d \epsilon_{0} / d w_{2}\right)+\left[M\left(\epsilon_{1}-1\right) /\left(\epsilon_{1}+2\right)\right] \\
\times\left[v_{1}+\left(d v / d w_{2}\right)\right],
\end{aligned}
$$

where $v_{1}$ and $\epsilon_{1}$ pertain to the pure solvent. The electronic polarization $P_{E}$ was calculated from $n_{\infty}$ in the usual manner, ${ }^{16,64}$ and the atomic polarization $P_{A}$ was calculated ${ }^{16}$ from the relationship given by Dasgupta and Smyth. ${ }^{43}$ Mean-square dipole moments were then calculated from

$$
\left\langle\mu^{2}\right\rangle=(9 k T / 4 \pi N)\left(P-P_{E}-P_{A}\right),
$$

where $N$ is the Avogadro number. Values of the dipole moment ratio were then calculated from $\left\langle\mu^{2}\right\rangle$, the number $n=2 x+2$ of bond dipoles, and the square of their moment $|m|=0.60 \mathrm{D} .{ }^{13,16}$ These results are shown in the third column of Table II. In order to determine the effect of including the correction factor suggested by the work of Onsager, ${ }^{66}$ values of $\left\langle\mu^{2}\right\rangle$ calculated from Eq. (3) were corrected according to

$\left\langle\mu^{2}\right\rangle_{\mathrm{corr}}=\left[\left(2 \epsilon_{0}+\epsilon_{\infty}\right)\left(\epsilon_{0}+2\right) / 3 \epsilon_{0}\left(\epsilon_{\infty}+2\right)\right]\left\langle\mu^{2}\right\rangle$,

where $\epsilon_{\infty}$, the infinite frequency dielectric constant was calculated from $^{43}$

$$
P_{E}+P_{A}=M v\left(\epsilon_{\infty}-1\right) /\left(\epsilon_{\infty}+2\right) \text {. }
$$

Dipole moment ratios calculated on this basis are given in column 4 of Table II. Representative results, at $25^{\circ} \mathrm{C}$, are shown by the left-filled circles in the upper portion of Fig. 2. These values differ by only approximately 0.015 unit from those calculated according to Eq. (3). In any case, the entire collection of results obtained in solution indi cate that $\left\langle\mu^{2}\right\rangle / \mathrm{nm}^{2}$ for PDMS chains is constant to within less than $3 \%$ for the cited range of degree of polymerization. For comparison, the effect of the degree of polymerization on the ratio $\left\langle r^{2}\right\rangle / n l^{2}$ is shown in the lower portion of this figure. The first illustration, the curve without experimental points, was calculated ${ }^{2-5}$ from the reported viscosity -mo-

\begin{tabular}{|c|c|c|c|c|}
\hline \multirow[b]{2}{*}{$\mathrm{T}\left({ }^{\circ} \mathrm{C}\right)$} & \multirow[b]{2}{*}{$x+1$} & \multicolumn{2}{|c|}{ Sol'n } & \multirow{2}{*}{$\begin{array}{l}\text { Undiluted } \\
\text { Eq. (6) }\end{array}$} \\
\hline & & Eq. (3) & Eq. (4) & \\
\hline \multirow[t]{5}{*}{$10,15^{a}$} & 97 & 0.387 & 0.402 & 0.314 \\
\hline & 162 & $\cdots$ & $\cdots$ & 0.308 \\
\hline & 188 & 0.377 & 0.392 & 0.306 \\
\hline & 239 & 0.377 & 0.392 & 0.305 \\
\hline & 1038 & 0.398 & 0.414 & 0.308 \\
\hline \multirow[t]{5}{*}{20} & 97 & 0.375 & 0.389 & 0.312 \\
\hline & 162 & $\cdots$ & $\cdots$ & 0.307 \\
\hline & 188 & 0.360 & 0.374 & 0.304 \\
\hline & 239 & 0.358 & 0.372 & 0.303 \\
\hline & 1038 & 0.367 & 0.382 & 0.307 \\
\hline \multirow[t]{5}{*}{25} & 97 & 0.361 & 0.374 & 0.311 \\
\hline & 162 & $\cdots$ & $\cdots$ & 0.305 \\
\hline & 188 & 0.381 & 0.395 & 0.302 \\
\hline & 239 & 0.357 & 0.370 & 0.302 \\
\hline & 1038 & 0.354 & 0.367 & 0.305 \\
\hline \multirow[t]{5}{*}{30} & 97 & 0.390 & 0.404 & 0.310 \\
\hline & 162 & $\cdots$ & $\cdots$ & 0.304 \\
\hline & 188 & 0.405 & 0.420 & 0.301 \\
\hline & 239 & 0.379 & 0.393 & 0.302 \\
\hline & 1038 & 0.414 & 0.429 & 0.305 \\
\hline \multirow[t]{5}{*}{40} & 97 & 0.406 & 0.420 & 0.308 \\
\hline & 162 & $\cdots$ & $\cdots$ & 0.303 \\
\hline & 188 & 0.389 & 0.403 & 0.299 \\
\hline & 239 & 0.389 & 0.402 & 0.300 \\
\hline & 1038 & 0.413 & 0.427 & 0.304 \\
\hline \multirow[t]{5}{*}{50} & 97 & 0.344 & 0.355 & 0.306 \\
\hline & 162 & $\cdots$ & $\cdots$ & 0.302 \\
\hline & 188 & 0.322 & 0.332 & 0.298 \\
\hline & 239 & 0.328 & 0.339 & 0.299 \\
\hline & 1038 & 0.359 & 0.371 & 0.302 \\
\hline \multirow[t]{5}{*}{60} & 97 & 0.407 & 0.420 & 0.306 \\
\hline & 162 & $\cdots$ & $\cdots$ & 0.301 \\
\hline & 188 & 0.369 & 0.380 & 0.297 \\
\hline & 239 & 0.412 & 0.425 & 0.297 \\
\hline & 1038 & 0.444 & 0.458 & 0.301 \\
\hline
\end{tabular}
lecular weight relationship ${ }^{51}$ for PDMS chains at

TABLE II. Values of the dipole moment ratio $\left\langle\mu^{2}\right\rangle /$ $n m^{2}$.

${ }^{2}$ In the case of the polymer solutions, the lowest temperature employed was $15^{\circ} \mathrm{C}$, rather than $10^{\circ} \mathrm{C}$. 
$20^{\circ} \mathrm{C}$ in benzene, a thermodynamically good solvent at this temperature, on the basis of the $\Theta$ temperature, $-7^{\circ} \mathrm{C}$ reported ${ }^{67}$ for this system. The second curve shown pertains to results obtained in the present study on PDMS chains at $25^{\circ} \mathrm{C}$ in toluene, a very good solvent judging from the $\Theta$ temperature, $-30^{\circ} \mathrm{C}$, characterizing this sys tem. ${ }^{67}$ In both cases, the ratio $\left\langle r^{2}\right\rangle / n l^{2}$ does increase markedly over the range of degree of polymerization over which $\left\langle\mu^{2}\right\rangle / \mathrm{nm}^{2}$ was found to be constant. Although there are no reported values of $\left\langle\gamma^{2}\right\rangle / n l^{2}$ for these chains in cyclohexane, the very low $\Theta$ temperature, $-81^{\circ} \mathrm{C}$, reported ${ }^{67}$ for this system establishes cyclohexane as the best presently known solvent for PDMS and thus $\left\langle r^{2}\right\rangle / n l^{2}$ would show an even more marked dependence on degree of polymerization than is observed in benzene or toluene. These results therefore clearly establish that, at least in the case of PDMS chains, excluded volume interactions, while having a pronounced effect on $\left\langle\gamma^{2}\right\rangle / n l^{2}$, have no effect at all on the dipole moment ratio.

The dipole moments of the PDMS samples in the

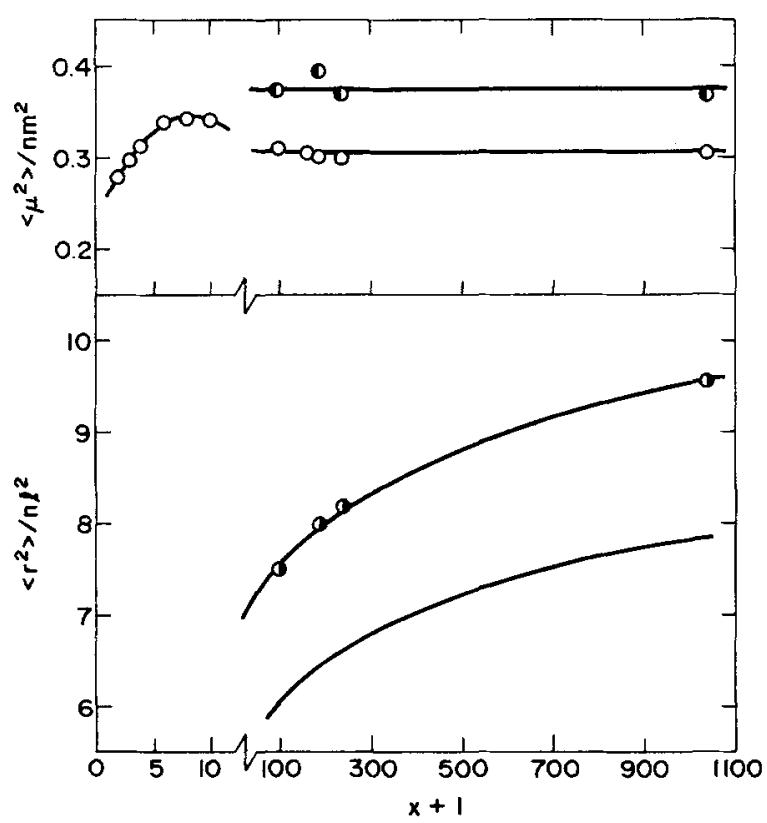

FIG. 2. Experimental values of the ratios $\left\langle\mu^{2}\right\rangle / \mathrm{nm}^{2}$ and $\left\langle r^{2}\right\rangle / n l^{2}$ for dimethylsiloxane chains shown as a function of the degree of polymerization. In the upper portion of the figure, left-filled circles refer to dielectric results obtained in cyclohexane at $25^{\circ} \mathrm{C}$ and open circles to results obtained in the absence of solvent at the same temperature. In the lower portion, the right filled circles and the associated curve refer to viscometric results obtained in toluene at $25^{\circ} \mathrm{C}$; the other curve shown was calculated from the intrinsic viscosity-molecular weight relationship reported ${ }^{51}$ for dimethylsiloxane chains in benzene at $20^{\circ} \mathrm{C}$. undiluted state were directly calculated from the Onsager equation ${ }^{66}$ :

$$
\left\langle\mu^{2}\right\rangle=(9 k T M v / 4 \pi N)\left[\left(\epsilon_{0}-\epsilon_{\infty}\right)\left(2 \epsilon_{0}+\epsilon_{\infty}\right) / \epsilon_{0}\left(\epsilon_{\infty}+2\right)^{2}\right] .
$$

Dipole moment ratios calculated therefrom are given in the last column of Table $I I$ and representative results, at $25^{\circ} \mathrm{C}$, are given by the open circles in the upper portion of Fig. 2. Included also, for purposes of comparison, are results ${ }^{16,43,56}$ per taining to very short chains in the undiluted state. Since chain molecules in the undiluted amorphous state are known to be unperturbed, ${ }^{6 B}$ the constancy of these values of the dipole moment ratio with increasing chain length was to be expected and these results are of interest more with regard to the specific value of $\left\langle\mu^{2}\right\rangle / \mathrm{nm}^{2}$ characterizing the chains under these conditions. First, as has already been pointed out, ${ }^{13,16}$ the dipole moment ratio for PDMS chains in general is quite small because the preferred conformation for these molecules approxi mates a closed figure of very small or zero dipole moment. The limiting value $\sim 0.30$ found for $\left\langle\mu^{2}\right\rangle /$ $\mathrm{nm}^{2}$ for PDMS chains in the undiluted state is in satisfactory agreement with the estimate previous ly calculated ${ }^{16}$ on the basis of other dielectric data $^{56}$ on these molecules. The value $\sim 0.40$ char acterizing the PDMS chains in cyclohexane is significantly larger and both of these experimental results exceed the value $\sim 0.23$ estimated ${ }^{13,16}$ for these chains using rotational isomeric state theory. $^{1}$ It is thought ${ }^{16}$ that much of this discrepancy is probably due to specific solvent effects, which are known ${ }^{51,57}$ to have a very marked effect on the dimensions of these chain molecules. The fact that cyclohexane has a value of the dielectric constant $2.0^{59}$ not very different from the value 2.8 obtained for the undiluted PDMS would seem to argue against a simple Coulombic origin of this complicating effect.

The value of the temperature coefficient $d \ln \left\langle\mu^{2}\right\rangle /$ $d T$ estimated $^{13}$ from rotational isomeric state theory is approximately $0.6 \times 10^{-3} \mathrm{deg}^{-1}$. Since this would indicate a change in $\left\langle\mu^{2}\right\rangle / \mathrm{nm}^{2}$ of only about 0.01 unit for the temperature range studied, the comparison of theory and experiment on this point can only be qualitative at best. As can be seen from Table II, the results obtained in cyclohexane suggest a zero or small positive temperature coefficient for $\left\langle\mu^{2}\right\rangle$. The results obtained in the undiluted state, on the other hand, suggest a small negative value; if, however, the small observed charge in the electronic polarization with temperature is considered an artifact and a constant value is used for this contribution to the polarization, then a zero or small positive value for $d \ln \left\langle\mu^{2}\right\rangle / d T$ again results. In any case, unfortunately, it must be admitted that the present experimental results 
are largely inconclusive with regard to the temperature coefficient of the dipole moments of PDMS chains.

\section{ACKNOWLEDGMENT}

It is a pleasure to acknowledge the financial support provided for this research by Grant GH-36205 from the National Science Foundation.

\section{${ }^{1}$ P. J. Flory, Statistical Mechanics of Chain Molecules} (Interscience, New York, 1969).

${ }^{2}$ P. J. Flory, J. Chem. Phys. 17, 303 (1949).

${ }^{3}$ T. G Fox, Jr. and P. J. Flory, J. Phys. Chem. 53, 197 (1949).

${ }^{4}$ P. J. Flory, Principles of Polymer Chemistry (Cornell U. P., Ithaca, NY, 1953).

${ }^{5}$ Reference 1, Chap. 2.

${ }^{6}$ W. J. Leonard, Jr., R. L. Jernigan, and P. J. Flory, J. Chem. Phys. 43, 2256 (1965)

${ }^{7}$ J. E. Mark and P. J. Flory, J. Am. Chem. Soc. 88, 3702 (1966).

${ }^{8}$ J. E. Mark, J. Am. Chem. Soc. 88, 3708 (1966).

${ }^{9}$ J. E. Mark, J. Polym. Sci. B 4, 825 (1966).

${ }^{10}$ K. Bak, G. Elefante, and J. E. Mark, J. Phys. Chem. 71, 4007 (1967).

${ }^{11}$ P. J. Flory and P. R. Schimmel, J. Am. Chem. Soc. 89, 6807 (1967).

${ }^{12}$ P. J. Flory and A. D. Williams, J. Polym. Sci. A-2 5, 399 (1967).

${ }^{13}$ J. E. Mark, J. Chem. Phys. 49, 1398 (1968).

${ }^{14}$ T. W. Bates and W. H. Stockmayer, Macromolecules 1, 12 (1968).

${ }^{15}$ P. R. Schimmel and J. G-M. Leung, Macromolecules 3, 704 (1970).

${ }^{16}$ C. Sutton and J. E. Mark, J. Chem. Phys. 54, 5011 (1971).

${ }^{17}$ J. E. Mark, J. Chem. Phys. 56, 451 (1972); J. Chem. Phys. 56, 458 (1972).

${ }^{18}$ F. E. Karasz (Ed.), Dielectric Properties of Polymers (Plenum, New York, 1972).

${ }^{19}$ J. E. Mark, J. Am. Chem. Soc. 94, 6645 (1972).

${ }^{20}$ J. Marchal and H. Benoit, J. Chim. Phys. 52, 818 (1955); J. Polym. Sci. 23, 223 (1957).

${ }^{21}$ W. H. Stockmayer, Pure Appl. Chem. 15, 539 (1967).

${ }^{22}$ K. Nagai and T. Ishikawa, Polym. J. 2, 416 (1971); see also Ref. 23.

${ }^{23}$ M. Doi, Polym. J. 3, 252 (1972).

${ }^{24}$ I. Sakurada and S. Lee, Z. Phys. Chem. B 43, 245 (1939).

${ }^{25}$ L. De Brouckère, D. Buess, J. De Bock, and J. Versluys, Bull. Soc. Chim. Belg. 64, 669 (1955).

${ }^{26}$ Y. Imamura, Nippon Kagaku Zasshi 76, 217 (1955).

${ }^{27}$ T. Uchida, Y. Kurita, and M. Kubo, J. Polym. Sci. 19, 365 (1956).

${ }^{28}$ T. Uchida, Y. Kurita, N. Koizumi, and M. Kubo, J. Polym. Sci. 21, 313 (1956).

${ }^{29}$ L. De Brouckère and L. K. H. Van Beek, Recl. Trav. Chim. Pays-Bas 75, 355 (1956).

${ }^{30}$ L. De Brouckère, D. Buess, and L. K. H. Van Beek, J. Polym. Sci. 23, 233 (1957).

${ }^{31} \mathrm{~L}$. De Brouckère and M. Mandel, Adv. Chem. Phys. 1, 77 (1958).

${ }^{32}$ C. G. Le Fèvre, R. J. W. Le Fèvre, and G. M. Parkins, J. Chem. Soc. (Lond.) 1958, 1468.
${ }^{33}$ C. G. Le Fèvre, R. J. W. Le Fèvre, and G. M. Parkins, J. Chem. Soc. (Lond.) 1960, 1814.

${ }^{34}$ M. Aroney, R. J. W. Le Fèvre, and G. M. Parkins, J. Chem. Soc. (Lond.) 1960, 2890.

${ }^{35}$ G. D. Loveluck, J. Chem. Soc. (Lond.) 1961, 4729.

${ }^{36}$ L. De Brouckère and A. Lecocq-Robert, Bull. Soc. Chim. Belg. 70, 549 (1961).

${ }^{37}$ A. Kotera, K. Suzuki, K. Matsumura, T. Nakano, T. Oyama, and U. Kambayashi, Bull. Chem. Soc. Jap. 35, 797 (1962).

${ }^{38}$ R. J. W. Le Fèvre and K. M. S. Sundaram, J. Chem. Soc. (Lond.) 1962, 1494.

${ }^{39}$ R. J. W. Le Fèvre and K. M. S. Sundaram, J. Chem. Soc. (Lond.) 1962, 4003.

${ }^{40}$ V. Magnasco, G. Dellepiane, and C. Rossi, Makromol. Chem. 65, 16 (1963).

${ }^{4 t}$ R. J. W. Le Fèvre and K. M. S. Sundaram, J. Chem. Soc. (Lond.) 1963, 1880.

${ }^{42}$ R. J. W. Le Fèvre and K. M. S. Sundaram, J. Chem. Soc. (Lond.) 1963, 3188.

${ }^{43}$ S. Dasgupta and C. P. Smyth, J. Chem. Phys. 47, 2911 (1967).

${ }^{44}$ See, for example, Ref. 17, which discusses the results presented in Ref. 38.

${ }^{45}$ J. Marchal and C. Lapp, J. Polym. Sci. 27, 571 (1958).

${ }^{46}$ For examples of specific solvent effects, see Refs. 47-52.

${ }^{47}$ A. R. Shultz and P. J. Flory, J. Polym. Sci. 15, 231 (1955).

${ }^{48}$ T. A. Orofino and J. W. Mickey, Jr., J. Chem. Phys. 38, 2512 (1963).

${ }^{49}$ U. Bianchi and V. Magnasco, J. Polym. Sci. 41, 177 (1959).

${ }^{50}$ K. J. Ivin, H. A. Ende, and G. Meyerhoff, Polymer 3, 129 (1962).

${ }^{51}$ V. Crescenzi and P. J. Flory, J. Am. Chem. Soc. 86, 141 (1964).

${ }^{52}$ T. A. Orofino, J. Chem. Phys. 45, 4310 (1966).

${ }^{53}$ R. Salovey, J. Polym. Sci. 50, S7 (1961).

${ }^{54}$ L. L. Burshtein and T. P. Stepanova, Polym. Sci. USSR 13, 81 (1971)

${ }^{55}$ R. O. Sauer and D. J. Mead, J. Am. Chem. Soc. 68, 1794 (1946).

${ }^{56}$ E. B. Baker, A. J. Barry, and M. J. Hunter, Ind. Eng. Chem. 38, 1117 (1946).

${ }^{57}$ C. U. Yu and J. E. Mark (unpublished).

${ }^{58}$ These four polymers were generously provided by the Dow Corning Corporation (sample designations DC200-100cs and DC200-5000cs) and the Union Carbide Corporation (Y4978 abd Y4979).

${ }^{59}$ J. Timmermans, Physico-Chemical Constants of Pure Organic Compounds (Elsevier, Amsterdam, 1965), Vols. 1 and 2.

${ }^{60}$ R. Mecke and K. Rosswog, Z. Elektrochem. 60, 47 (1956).

${ }^{61}$ H. H. Landolt, Landolt-Börnstein: Zahlenwerte und Funktionen aus Phys., Chem., Astron., Geophys., und Tech. (Springer, Berlin, 1959), Vol. II, Part 6.

${ }^{62}$ A. J. Barry, J. Appl. Phys. 17, 1020 (1946).

${ }^{63}$ A. Y. Korolev, K. A. Andrianov, L. S. Utesheva, and T. E. Vredenskaya, Dokl. Akad. Nauk SSSR 89, 65 (1953).

${ }^{64}$ C. P. Smyth, Dielectric Behavior and Structure (McGraw-Hill, New York, 1955).

${ }^{65}$ I. F. Halverstadt and W. D. Kumler, J. Am. Chem. Soc. 64, 2988 (1942).

${ }^{66}$ L. Onsager, J. Am. Chem. Soc. 58, 1486 (1936).

${ }^{67}$ N. Kuwahara, Y. Miyake, M. Kaneko, and J. Furuichi, Rep. Prog. Polym. Phys. Jap. 5, 1 (1962).

${ }^{68}$ P. J. Flory, Special Lectures, IUPAC International Symposium on Macromolecular Chemistry, Helsinki 1972 (Butterworths, London, 1973). 